\title{
Obstacles to the development of the agricultural sector of economics and ways to overcome them
}

\author{
Alfiya Kuznetsova ${ }^{1, *}$, Almir Askarov ${ }^{1}$, and Andrei Svetlakov ${ }^{2}$ \\ ${ }^{1}$ Bashkir State Agrarian University, 450001, 50-letiya Octyabrya street, Ufa, Russia \\ 2 Perm State Agrarian and Technological University named after D.N. Pryanishnikova, \\ 614990, Petropavlovskaya street, 23, Perm, Russia
}

\begin{abstract}
The article discusses the factors and problems that have a negative impact on the indicators of economic efficiency of the industry and, thus, hinder the sustainable development of rural areas, and also suggests a number of measures to overcome them. The methods of statistical data analysis and the method of aligning time series are used in the work. Large-scale production, on the one hand, entails an increase in labor productivity, and, on the other hand, generates rural unemployment. It was revealed that high-tech methods of agricultural production lead to an increase in the cost of manufactured products, both in a steady increase in prices for energy resources and concentrated feed, which increases the level of risks in the agricultural business. In addition, non-observance of the norms of crop rotation of sunflower crops on the same land plots entails damage to soil fertility. Such a strategic planning system is needed as part of the legal framework of public administration, which would create the conditions for the formation of healthy competition of manufactured products not only domestically, but also on the world market.
\end{abstract}

\section{Introduction}

In the material «The village of the republic is developing a development strategy», there are such words of the former Head of the Republic of Bashkortostan Rustem Khamitov, said back in 2013, about how he sees the future of agriculture and rural territories of the republic: «... we are still in a fever. We are still in the search stage ... Which way to go? To be honest, I have no answer to this question»[1]. Further, Rustem Khamitov adds that agriculture $« \ldots$ is poorly managed and not well funded ... we often go from one fairly low result to another fairly low result». Thus, he admitted that there was no clearly calibrated state agrarian policy, neither at the level of the Russian Federation, nor at the regional level.

So many years have passed, but the situation has not changed much since then. The main reason for this, in our opinion, is that our officials are continuing to aggressively

* Corresponding author: alfia 2009@mail.ru 
promote Western technologies that «work» not in increasing the competitiveness of the industry in the foreign market, but in the interests of foreign companies. Here is a literally «fresh» example - at the end of February, the newspaper «Respublika Bashkortostan» published material about the recently launched robotic farm in the Abzelilovsky district, for almost half a billion rubles [2].

What are the consequences of this event? Firstly, «... the wage fund does not exceed 23 percent of the cost of milk production»", while in economically developed countries the share of wages in the price of goods exceeds $50 \%$. Secondly, "l... the state subsidizes the purchase of technological equipment» (from a Dutch company). The result - six milking robots serving 400 cows (with a service rate of 66.7 cows) replaced 10 machine milking operators (the service rate by one operator in the republic's farms averaged 41.5 cows in 2018 ) with an annual salary of 2.2 million rubles («saving» on labor remuneration). Now, in order to employ the remaining 10 rural residents, it is necessary to allocate at least 10 million rubles from the budget of the region. In other words, these 10 million rubles will make up the «net» loss of the regional budget - this is exactly the amount obtained when, for example, a grant is allocated to a potential farmer to create a dairy farm - he must employ one worker per every 1 million rubles of his grant.

Another problem requiring a more balanced approach is investment plans for the construction of mega-farms (following the example of the United States) in the Republic of Bashkortostan, where, as with other types of resources, the «Law of diminishing returns» applies, that is, starting with which about the size of the complex (farm), economies of scale no longer cover the increase in costs associated with the implementation of a business project. So, according to the results of the study Yu.N. Nikulina, based on the materials of the Leningrad region, the concentration (localization) of a large number of cows at one facility has a negative impact on the competitiveness of milk produced, and the profitability curve of the final product in this case has the form of an «inverted» parabola» [3].

The construction of mega-farms, as well as «robotization», leads to the «destruction» of jobs in the village, the reality of which can be seen in the example of a large dairy farm, where 20 workers and managers serve a farm for 2450 cows (Pennsylvania, USA) [4]. In relation to the conditions of the republic, the construction of one such mega-farm means the «liquidation» of approximately 10 existing dairy farms, as well as the «destruction» of at least 40 jobs - the «net» losses of the regional budget associated with the employment of rural residents who become unemployed will amount to approximately 40 million rubles.

Such an investment policy continues to operate, despite the presence of serious theoretical research by domestic scientists [3, 5], including the authors of this article, devoted to determining the optimal productivity of cows, the cost of milk at various levels of feeding, a rational level of localization of livestock and practical experience in obtaining competitive milk while maintaining extensive livestock technology [6]. Republican industry leaders follow the principle: «the higher, the better and more efficient», encouraging farm managers for high crop yields and animal productivity, which prevents the wider use of the so-called «free type of resources» [7].

In crop production, this leads to disruption of the system of scientifically based crop rotation, which causes great damage to soil fertility, in livestock breeding - to a massive transition to year-round stall keeping of livestock, which leads to a significant increase in feed costs. Thus, cattle-breeding complexes, even not the largest ones, cannot or do not want to use a practically free source of highly nutritious feeds - summer grazing of cattle decreases from year to year. Accordingly, green grass (the cheapest and, at the same time, the most nutritious feed) is replaced by grain fodder and purchased compound feeds (the most expensive at the moment). Thus, according to statistics, the share of concentrated feed in the annual diet of cows in 2018 reached an unacceptably high value - 42\% against scientifically based $30-35 \%$. Accordingly, the share of other cheaper types of feed, 
especially green - annual and perennial grasses, as well as grazing grass - fell almost twice lower than scientifically based standards - $13 \%$.

All this impedes the cost reduction of production, in contrast to other countries, particularly in Europe, where the choice of technology comes first in the cost of a unit of production and «... there is always a choice - to use an expensive or simpler tractor, or maybe even a manual one work» [8].

The purpose and objectives of the study - analyze the dynamics of agricultural development in the Republic of Bashkortostan, identify factors that negatively affect the indicators of its economic efficiency and, thus, impede the sustainable functioning of the industry, as well as present theoretically substantiated and proven practice proposals for overcoming them.

\section{Research framework, material and sources.}

The study is devoted to identifying problems that impede the sustainable functioning and development of agriculture and rural economy. The study used data from statistical compendiums and summary annual reports of agricultural organizations subordinate to the Ministry of Agriculture of the Republic of Bashkortostan for 2010-2018. A number of measures are proposed, through the implementation of which it is expected to raise the level of sustainability of the functioning and development of agriculture and rural areas of the region and the country as a whole.

Research work methods. As the main research methods used methods of statistical data analysis, as well as the method of aligning time series. Since the purpose of the study is to identify factors that negatively affect the indicators of economic efficiency of agricultural production as a business and the sustainability of rural development, we focused on the use of factual information, which has a high degree of verification.

The relevance of the study lies in the fact that it is devoted to identifying problems that impede the sustainable functioning and development of the domestic agricultural sector, which is the basis for the well-being of rural areas. Despite the presence of serious theoretical research by scientists, as well as practical experience in obtaining competitive agricultural products while maintaining traditional technologies, including in the economically developed countries of Europe, our country's industry leaders largely ignore them. This means the need for research aimed at developing a forecasting and planning methodology at the industry level, designed to provide the optimal solution to socioeconomic problems in rural areas.

\section{Justification of management decisions for the future}

The negative phenomena identified above in the agricultural sector of the economy mean, according to Andrei Klepach, member of the Board of the Free Economic Society of Russia, Deputy Chairman of Vnesheconombank, that «... the system of long-term strategic management did not work out for us»[9]. The Academician of the Russian Academy of Sciences Sergey Glazyev also agrees with him. In his opinion, «... the government does not even begin to execute it» [10], despite the fact that strategic planning as the legal basis of public administration is designed to create conditions so that domestic producers can compete «on equal terms» not only domestically, but also worldwide the market.

What this lack of state regulation of the most important parameters for the development of agro-industrial production, stipulated by the Law on Strategic Planning in the Russian Federation, leads to can be seen from table 1, where correlation-regression equations show changes in production costs of some of the most important agricultural organizations of the Republic Bashkortostan types of products for 2010-2018. 
Table 1. The Dynamics of the cost of production, rubles / c.

\begin{tabular}{|l|l|c|c|c|}
\hline Indicators & \multicolumn{1}{c|}{$\begin{array}{c}\text { The equation } \\
\text { regression }\end{array}$} & $\begin{array}{c}\text { Coefficient } \\
\text { correlations }\end{array}$ & $\begin{array}{c}\text { Criterion } \\
\text { Fisher }\end{array}$ & $\begin{array}{c}2018 \text { in\% } \\
\text { by 2010 }\end{array}$ \\
\hline Corn & $\mathrm{Y}=426,3+21,88 \cdot \mathrm{t}$ & 0,754 & 9,2 & 140 \\
\hline Sugar beet & $\mathrm{Y}=128,1+8,75 \cdot \mathrm{t}$ & 0,460 & 1,9 & 150 \\
\hline Sunflower & $\mathrm{Y}=646,4+79,12 \cdot \mathrm{t}$ & 0,793 & 12 & 190 \\
\hline Potatoes & $\mathrm{Y}=668,7+26,63 \cdot \mathrm{t}$ & 0,381 & 1,2 & 130 \\
\hline Milk & $\mathrm{Y}=864,8+98,58 \cdot \mathrm{t}$ & 0,975 & 136 & 180 \\
\hline Cattle growth & $\mathrm{Y}=5967+757,9 \cdot \mathrm{t}$ & 0,995 & 686 & 109 \\
\hline
\end{tabular}

Table 2 describes the dynamics of growth in prices for the purchase of energy resources by agricultural organizations of the republic for the same years [11], as the main reason explaining the catastrophic consequences for agricultural production.

Table 2. The Dynamics of prices for energy resources for agricultural organizations.

\begin{tabular}{|l|c|c|c|c|}
\hline Indicators & \multicolumn{1}{|c|}{$\begin{array}{c}\text { The equation } \\
\text { regression }\end{array}$} & $\begin{array}{c}\text { Coefficient } \\
\text { correlations }\end{array}$ & $\begin{array}{c}\text { Criterion } \\
\text { Fisher }\end{array}$ & $\begin{array}{c}2018 \text { in\% } \\
\text { by 2010 }\end{array}$ \\
\hline Diesel fuel, rubles / kg & $\mathrm{Y}=13,07+3,563 \cdot \mathrm{t}$ & 0,990 & 351 & 270 \\
\hline Gasoline, rub./kg & $\mathrm{Y}=18,45+3,248 \cdot \mathbf{t}$ & 0,991 & 379 & 220 \\
\hline Electricity, rubles / kW & $\mathrm{Y}=2,522+0,232 \cdot \mathrm{t}$ & 0,992 & 454 & 170 \\
\hline Natural gas, rubles / $\mathrm{m} 3$ & $\mathrm{Y}=2,898+0,356 \cdot \mathrm{t}$ & 0,987 & 274 & 190 \\
\hline
\end{tabular}

As can be seen from the table, the growth dynamics of domestic prices for energy resources is very stable, there are practically no annual fluctuations - the correlation coefficient is close to unity (1). In contrast, statistical models of the cost of agricultural products are characterized by much less stability. This, in turn, causes significant fluctuations in the final result of the activities of agricultural formations in the form of profitability of the products they sell, which is clearly visible in the graphs (figure below).

In the given graphs, the width of the «corridors» characterizing the «spread» in the profitability indicator by years (the value of annual fluctuations) is very large, which indicates a high level of risks in the agricultural business. In addition, for three of the six traditional types of agricultural products that form the basis of the economy for most agricultural organizations of the Republic of Bashkortostan, the dynamics of the indicator is negative. This is the first thing you need to pay attention to leaders of all ranks.

And second, the largest natural monopolies that make up the country's fuel and energy complex are the main «brake» on the way to increasing the stability of functioning, not to mention the sustainability of the development of all agricultural commodity producers, regardless of their legal form. Thus, they continue to contribute to maintaining the food dependence of the Russian Federation on foreign countries, preventing the agrarians of their country from raising the competitiveness of products at cost, respectively at a price.

A comparative analysis of prices for the main types of agricultural products in recent years shows that the agrarian formations of the Republic of Bashkortostan still have a level of price competitiveness sufficient for effective functioning, including in the world grain, potato and sunflower market [12]. 


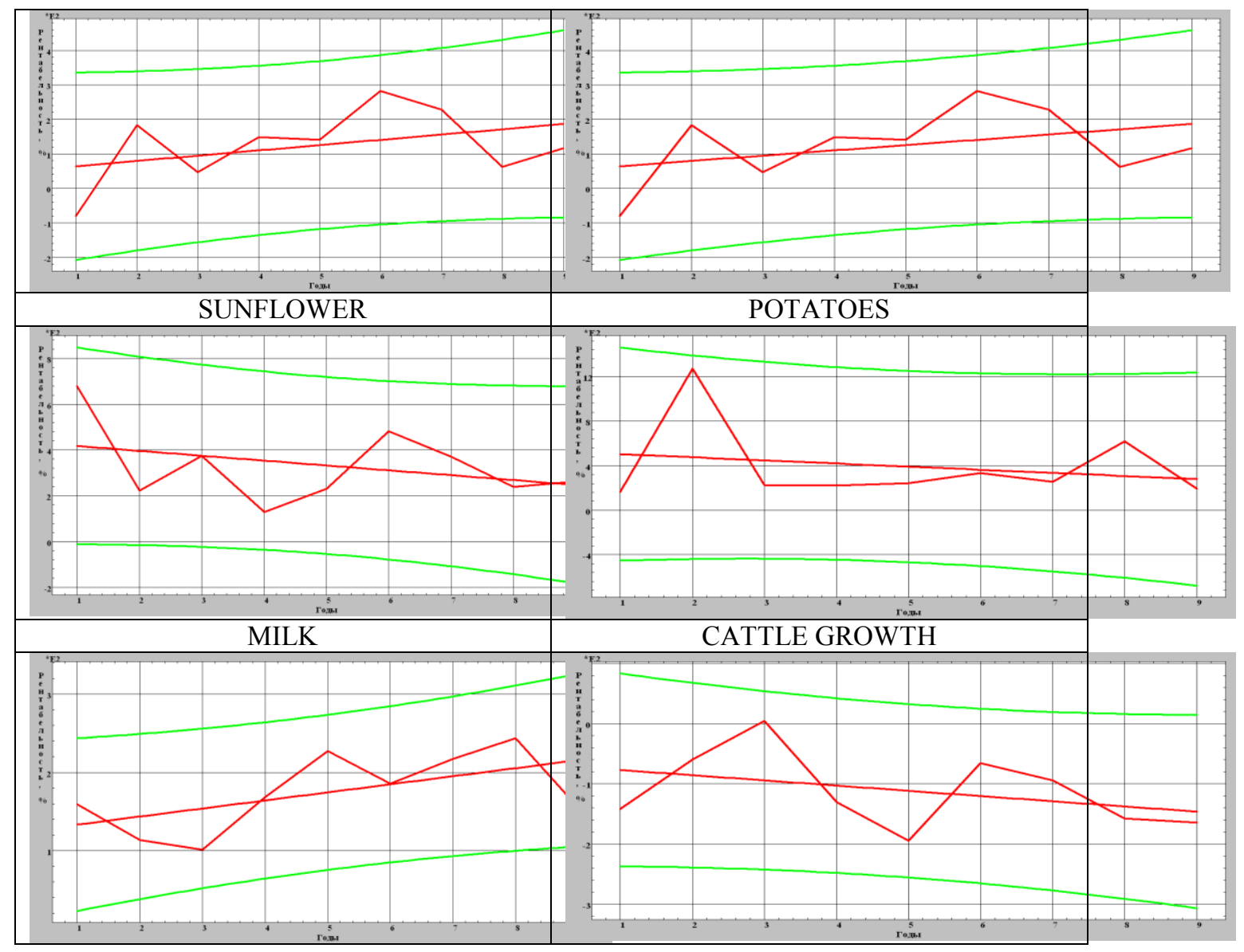

Figure 1. Dynamics of the level of profitability of products agricultural organizations of the republic for 2010-2018.

However, poor planning or its complete absence can lead to a loss of competitiveness, especially sunflower, as happened with sugar obtained from sugar beet roots. This is a striking example of the lack of long-term planning, the result of the «race» for high productivity due to the introduction of large doses of mineral fertilizers, regardless of the costs of them. Here is what the above-mentioned farmer said: «The German farmer has two alternatives ... to close the enterprise or increase its efficiency by ... reducing costs per unit of production» [8].

As for sunflower, the production of which in the republic is to the detriment of soil fertility - in some farms, its crops occupy up to $40-50 \%$ of arable land, against scientifically based $10-15 \%$ - it is time to take measures to reduce its area and restore optimal crop rotation according to the example of some regions of Russia, where purely administrative measures are being taken in relation to agro-offenders. The same measures to restrain the expansion of crops will be required, perhaps, in relation to rapeseed, the production of which is fully export-oriented, while European countries partially or completely refuse, for various reasons, this crop. In this regard, the district information and consultation centers could recommend the structure of commodity production that is optimal for a particular farm, guaranteeing maximum profit - margin.

Under such conditions, the agrarian formations of the republic, as well as Russia as a 
whole, are powerless - the solution of issues of inter-industry relations is possible only at the state level by creating conditions for equal partnership between agriculture and industrial sectors. For example, what can domestic producers do to increase competitiveness in the conditions: firstly, when domestic prices for energy resources exceed export prices by up to two times (with the exception of natural gas advertised as «public property») and when the domestic price per ton of active mineral fertilizers 1.2-1.6 times the export price of fertilizers; secondly, relatively high interest rates on loans compared with the same England $(0.5 \%)$ or with Japan, where for decades the rate did not exceed 2\%; thirdly, excise taxes on fuel - in the USA, Canada, the EU, Belarus and many other countries of the world agricultural producers receive fuel without excise tax or part of it [12].

It is absolutely clear - in such conditions, the efforts of agricultural producers should be aimed at finding and implementing their internal reserves. First of all, this concerns the search for reserves to reduce direct variable costs, with wider use of the «free type of resources» [7] due to: a) creation (restoration) of optimal crop rotation based on diversification of crops; b) the maximum possible use of grass from natural forage land.

We already spoke in previous works about the problems of the development of the dairy industry in the Russian Federation [15], as well as about the general problems of livestock development [16], which lead to problems of motivation of workers to work [17].

\section{Conclusions and offers}

As can be seen from the above, ignoring the system of long-term strategic management, carried out precisely through planning $[9,10]$, in agriculture led to significant negative consequences, which include the frequent bankruptcies of agricultural processing enterprises, which does not add stability to the functioning and the development of the entire agricultural sector of the country.

The scenario disclosed in the work is unacceptable for the country, it should not be allowed under any circumstances, since this means that the environmental and social components of the system - agriculture, are even closer to the stage of catastrophe or a jump-like transition to an even worse state. The amount of environmental and social damage in this case may turn out to be «unbearable» for the economy of the country as a whole, which will mean disaster for the whole society.

In conclusion - a few suggestions to improve the sustainability of the functioning and development of agriculture in the Republic of Bashkortostan:

1) conduct an analysis of the territorial organization of the rural population and households in each municipal region of the republic in order to identify emerging (beginning to appear) trends in their changes;

2) organize training (advanced training) of employees and specialists of municipalities in the practice of applying forecasting methods, as well as familiarizing them with already adopted programs related to the development of agricultural production and rural territories at the federal, republican and municipal levels;

3) make a forecast (scenarios) of the development of this process, indicating promising (growing), highly likely to persist in the next 10-15-20 years, unpromising or disappearing in the next 5-10-15 years of settlements;

$4)$ in all villages and villages to build, following the example of other countries $[6,13$, 14] small and medium-sized farms for dairy herd cows at: 50 (Holland), 100-200 (Norway, Canada), 300-350 (New Zealand), restore old buildings, "legalize" the allocation of land for the construction of comfortable housing, as well as for farming;

In the implementation of the above measures, the participation of both scientific workers and employees and specialists of the municipalities themselves is mandatory (on 
the principle of participativeness or the participation of «performers» in the transformation of villages and villages).

\section{References}

1. The village of the republic is developing a development strategy, Newspaper «Respublic of Bashkortostan, 140 (2013)

2. I. Akhiyarov, Newspaper "Republic of Bashkortostan", 24 (2020)

3. Yu. N. Nikulina, Influence of the concentration of milk production on its competitiveness in agricultural organizations of the Leningrad region, Abstract. diss. cand. econ. sciences (St. Petersburg, Pushkin, 2011)

4. I. Kryachkov, Economist, 12, 88-89. (2005)

5. F.S. Khaziahmetov Rational feeding of animals (SPb., 2011)

6. A. Chernov New Zealand - the dairy leader (2013)

7. T. Sazonov Free resource for increasing profitability in agriculture (2019)

8. I. Romanov, Russian Land, 36 (2003)

9. A. A. Klepach, New model of economic growth. What's new? (2016)

10. S. Glazyev, Arguments and Facts, 3 (2020)

11. Agriculture, hunting and forestry of the Republic of Bashkortostan. Statistical Digest. Ufa, 2010, 2014, 2019.

12. N.I. Shagayda, V.Ya. Uzun, Economy of agricultural and processing enterprises, 9, 2-9 (2018)

13. V. Melnichenko, Arguments of the Week, 34 (678) (2019)

14. V.D. Mitrakova, Family dairy farms abroad (2018)

15. A.R. Kuznetsova, R.H. Avzalov, M.R. Avzalov, R.U. Gusmanov, A.A. Askarov, The state and problems of increasing milk production in Russian Federation. IOP Conference Series: Earth and Environmental Science, 72033 (2019)

16. A. Kuznetsova, M. Avzalov, D. Gorbunov, E. Stovba, Trends and status of agribusiness in animal husbandry of the Russian Federation. Hradec Economic Days Double-blind peer-reviewed proceedings part I. of the international scientific conference Hradec Economic Days, 519-527(2019)

17. A.R. Kuznetsova, Z. Zagirova, Zh. Omarhanova, Problems of poverty and motivation of workers to labour in the field of agriculture as effects of stagnant economy, Hradec Economic Days Double-blind peer-reviewed proceedings part I. of the international scientific conference, 523-538 (2018) 